ERRATUM

\title{
Impact of metformin versus the prandial insulin secretagogue, repaglinide, on fasting and postprandial glucose and lipid responses in non-obese patients with type 2 diabetes
}

Søren S Lund ${ }^{1}$, Lise Tarnow ${ }^{1}$, Merete Frandsen ${ }^{1}$, Ulla M Smidt ${ }^{1}$, Oluf Pedersen ${ }^{1,2}$, Hans-Henrik Parving ${ }^{2,3}$ and Allan A Vaag ${ }^{1,4}$

${ }^{1}$ Steno Diabetes Center, Niels Steensens Vej 2, 2820 Gentofte, Denmark, ${ }^{2}$ Faculty of Health Sciences, University of Aarhus, Aarhus, Denmark, ${ }^{3}$ Department of Medical Endocrinology, Rigshospitalet, University of Copenhagen, 2100 Copenhagen, Denmark and ${ }^{4}$ Department of Endocrinology, University of Lund, S-20502 Malmö, Sweden

(Correspondence should be addressed to S S Lund who is now at Boehringer Ingelheim, Ingelheim, Germany; Email: sslund@dadlnet.dk)

The authors and the journal apologise for an error in this article published in the European Journal of Endocrinology 2008 Vol $\mathbf{1 5 8}$ pp 35-46. In the second paragraph under the section 'Statistical analysis', on page 37 , the formula for calculating the AUC should be as follows:

$1.5 \mathrm{~h} \times\left(0.5 \times\right.$ concentration $_{\mathrm{t}=0 \mathrm{~h}}+$ concentration $_{\mathrm{t}=1.5 \mathrm{~h}}+$ concentration $_{\mathrm{t}=3.0 \mathrm{~h}}+$ concentration $_{\mathrm{t}=4.5 \mathrm{~h}}+0.5 \times$ concentration $\left._{\mathrm{t}=6.0 \mathrm{~h}}\right)$

and not as published. The full sentence should therefore read:

Total area under the curve (AUC) during $0-6 \mathrm{~h}$ was estimated as the postprandial summary variable and calculated by the trapezoidal rule in units of concentration $\times$ hours, i.e. $1.5 \mathrm{~h} \times(0.5 \times$ concentration $_{\mathrm{t}=0 \mathrm{~h}}+$ concentration $_{\mathrm{t}=1.5 \mathrm{~h}}+$ concentration $_{\mathrm{t}=3.0 \mathrm{~h}}+$ concentration $_{\mathrm{t}=4.5 \mathrm{~h}}+0.5 \times$ concentration $_{\mathrm{t}=6.0 \mathrm{~h}}$ ).

European Journal of Endocrinology 165831 